\title{
Space Weather opportunities from the $S$ warm mission including near real time applications
}

\author{
Claudia Stolle ${ }^{1,3}$, Rune Floberghagen ${ }^{2}$, Hermann Lühr ${ }^{3}$, Stefan Maus ${ }^{4}$, D. J. Knudsen ${ }^{5}$, Patrick Alken ${ }^{4}$, \\ Eelco Doornbos ${ }^{6}$, Brian Hamilton ${ }^{7}$, Alan W. P. Thomson ${ }^{7}$, and Pieter N. Visser ${ }^{6}$ \\ ${ }^{1}$ Technical University of Denmark, DTU Space, Lyngby, Denmark \\ ${ }^{2}$ Directorate of Earth Observation Programmes, ESRIN, Frascati, Italy \\ ${ }^{3}$ Helmholtz-Centre Potsdam, GFZ German Research Center for Geosciences, Germany \\ ${ }^{4}$ National Geophysical Data Center, NOAA, USA \\ ${ }^{5}$ University of Calgary, Calgary, $A B$, Canada \\ ${ }^{6}$ Delft University of Technology, Netherlands \\ ${ }^{7}$ British Geological Survey, Edinburgh, Scotland, UK
}

(Received March 27, 2013; Revised September 30, 2013; Accepted October 21, 2013; Online published November 22, 2013)

Sophisticated space weather monitoring aims at nowcasting and predicting solar-terrestrial interactions because their effects on the ionosphere and upper atmosphere may seriously impact advanced technology. Operating alert infrastructures rely heavily on ground-based measurements and satellite observations of the solar and interplanetary conditions. New opportunities lie in the implementation of in-situ observations of the ionosphere and upper atmosphere onboard low Earth orbiting (LEO) satellites. The multi-satellite mission Swarm is equipped with several instruments which will observe electromagnetic and atmospheric parameters of the near Earth space environment. Taking advantage of the multi-disciplinary measurements and the mission constellation different Swarm products have been defined or demonstrate great potential for further development of novel space weather products. Examples are satellite based magnetic indices monitoring effects of the magnetospheric ring current or the polar electrojet, polar maps of ionospheric conductance and plasma convection, indicators of energy deposition like Poynting flux, or the prediction of post sunset equatorial plasma irregularities. Providing these products in timely manner will add significant value in monitoring present space weather and helping to predict the evolution of several magnetic and ionospheric events. Swarm will be a demonstrator mission for the valuable application of LEO satellite observations for space weather monitoring tools.

Key words: Ionosphere, thermosphere, geomagnetic field, solar-terrestrial coupling, space weather, Swarm, low Earth orbiting satellites.

\section{Introduction}

Timely monitoring and prediction of solar-terrestrial processes is increasingly important for our society which depends more and more on advanced technology that relies on continuous power availability, radio wave communication and navigation, and satellite operation. Enhanced solar wind and solar radiation input energy into near-Earth space result, for example, in strong electric currents flowing in the magnetosphere and ionosphere, and in significant plasma density structuring or alterations of neutral composition, density and winds in the upper atmosphere (e.g., Tsurutani et al., 1997; Prölss, 2011). Such periods of enhanced activity are often called magnetic storms since they cause rapid variations of the geomagnetic field of up to several hundred nanotesla within a few minutes. Strong variations of ionospheric currents, such as the auroral electrojet, cause induced electric fields in the conducting solid Earth that may harm power grid systems (e.g. Kappmenman, 1989;

Copyright (C) The Society of Geomagnetism and Earth, Planetary and Space Sciences (SGEPSS); The Seismological Society of Japan; The Volcanological Society of Japan; The Geodetic Society of Japan; The Japanese Society for Planetary Sciences; TERRAPUB.

doi:10.5047/eps.2013.10.002
Thomson, 2007). Variations in the strength and direction of the geomagnetic field, that are caused e.g. by the polar electrojets or the magnetospheric ring current may disturb navigation activities that are based on precise magnetic maps, e.g., for aviation or exploration directional drilling activities. Steep plasma density gradients in the ionosphere and plasmasphere bend and scatter trans-ionospheric radio waves that are used for satellite-based navigation, e.g., by the Global Positioning System (GPS) and the future Galileo. Such irregularities result in navigational errors that are not included in ionospheric correction models implemented in commercial GPS receivers and may even lead to signal outage and radio wave scintillations (e.g., Basu et al., 2002). Scintillations, such as equatorial F region plasma irregularities, also have to be considered as regular disturbances, that are independent of magnetic storm activity. Irregular thermospheric density enhancements also have significant effects on satellite drag and space debris monitoring.

For the purpose of real time monitoring and predicting space weather many national and international initiatives have been established. Such activities reach from specific tools for quantifying individual processes, partly 

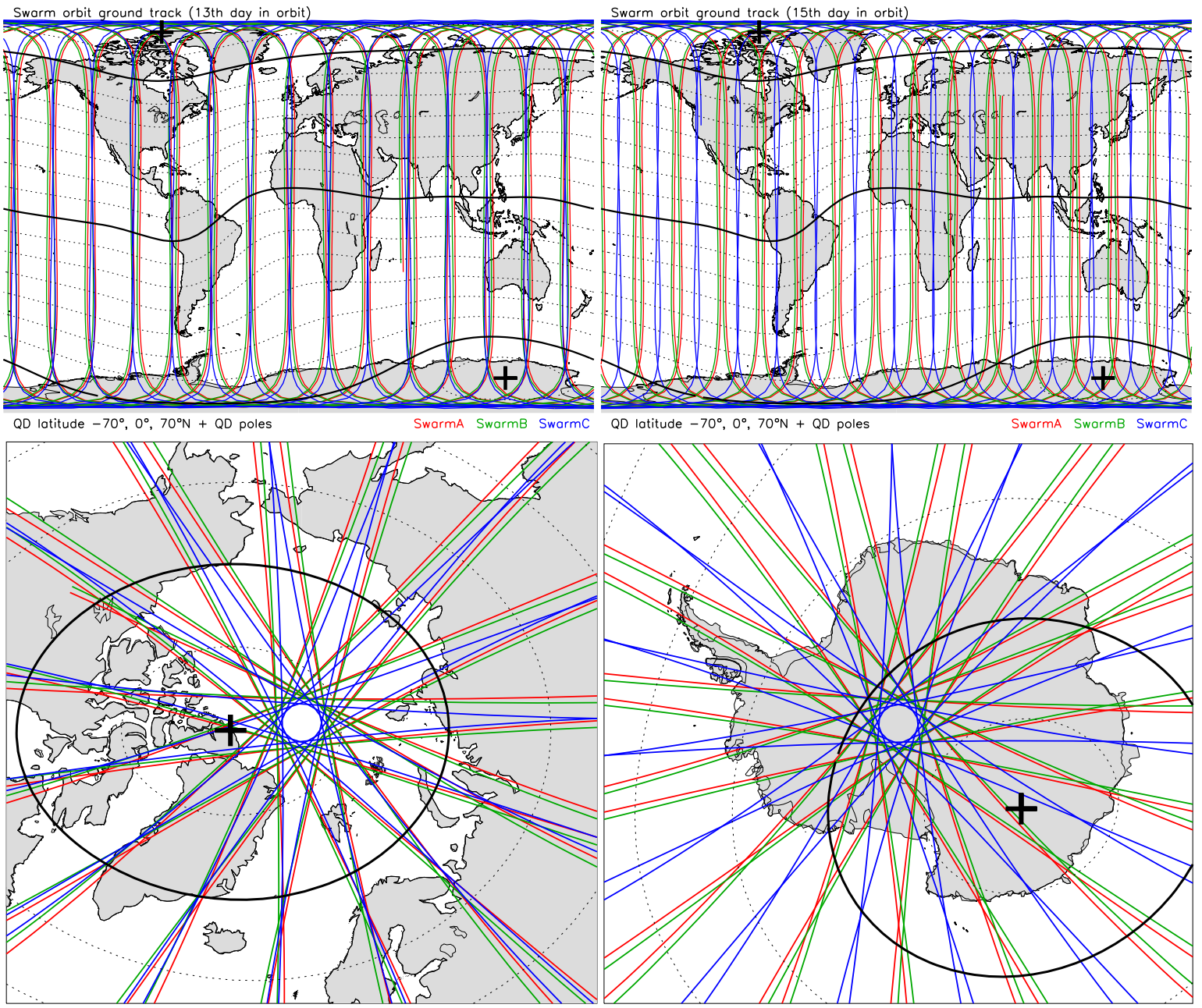

Fig. 1. Global coverage of the Swarm satellites for one day after 13 days in orbit (left) and 15 days in orbit (right) (Olsen, 2004) Red: Swarm A, Green: Swarm B, Blue: Swarm C. Orbits are shown globally (upper panels) and over the north and south pole (lower panels). Black lines indicate the location of the equator and $70^{\circ}$ north and south in quasi-dipole (QD) coordinates. Crosses indicate the location of the QD poles. (See online version for colored figures.)

locally specified, among others monitoring the auroral oval, for example by the Scandinavian magnetic magnetometer network (e.g., Johnson, 2013), predicting indices for ground induced currents in Scandinavia "GIC Now!" (http://aurora.fmi.fi/gic_service/english/), the ionospheric plasma distribution in mid-latitudes based on a network of European ionosondes (e.g., Belehaki et al., 2006), maps of Total Electron Content (TEC) from ground-based TEC networks (Jakowski et al., 2011) or the prediction of the ionospheric equatorial electric field from solar wind parameters (Manoj and Maus, 2012). Largely sophisticated applications are assimilative efforts of ground- and satellitebased observations into physical background models that allow the specification and prediction of the global ionosphere (e.g., Schunk et al., 2005).

Observations from Low-Earth Orbiting (LEO) satellites have often played a role for space weather activities. These are mainly GPS radio occultation experiments such as from the COSMIC satellites (http://www.cosmic.ucar.edu/) being an important data source for global assimilation efforts. Monitoring of the auroral oval is achieved from optical measurements, e.g., from the NOAA Polar Orbiting Environmental Satellites programm PEOS (http://www.swpc.noaa.gov/pmap/). The Swarm constellation mission (Friis-Christensen et al., 2006, 2008) operated by the European Space Agency (ESA) and with expected launch in 2013, provides a good opportunity for integration and development of novel products describing space weather conditions based on observations from LEO satellites. Equipped with high precision observations of the magnetic, plasma and neutral environment in near-Earth space, it will serve as a demonstrator mission for future LEO satellite programmes used in space weather monitoring.

Section 2 describes constellation aspects of the Swarm mission, briefly mentions its relevance for space weather monitoring. Scientific Swarm data products are listed in Section 3, and the potential for novel satellite-based data tools is discussed, followed by a summary and discussion on the missions readiness for timely provision of its products in Section 4.

\section{Swarm Constellation}

Orbital configuration is an important consideration when satellite-based space weather products are generated for monitoring the ionosphere and thermosphere. The Swarm 


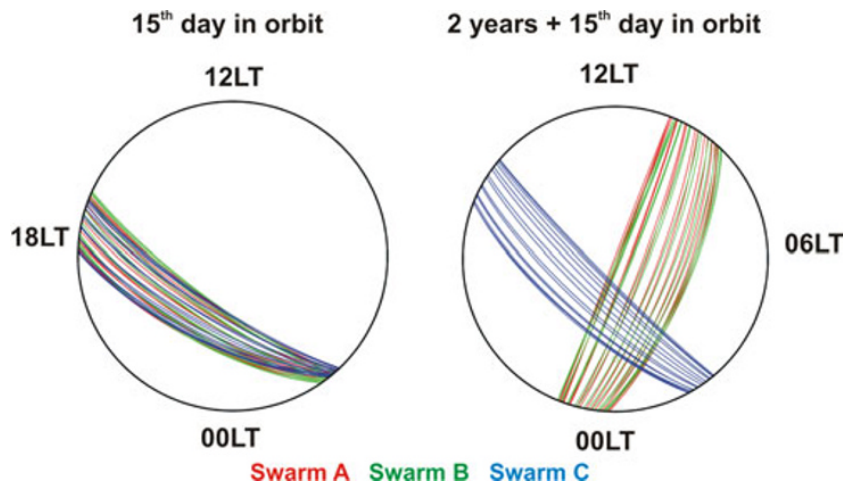

Fig. 2. Magnetic local time coverage of the Swarm satellites for one day in orbit, corresponding to 15 days in orbit and to 2 years and 15 days in orbit. (See online version for colored figures.)

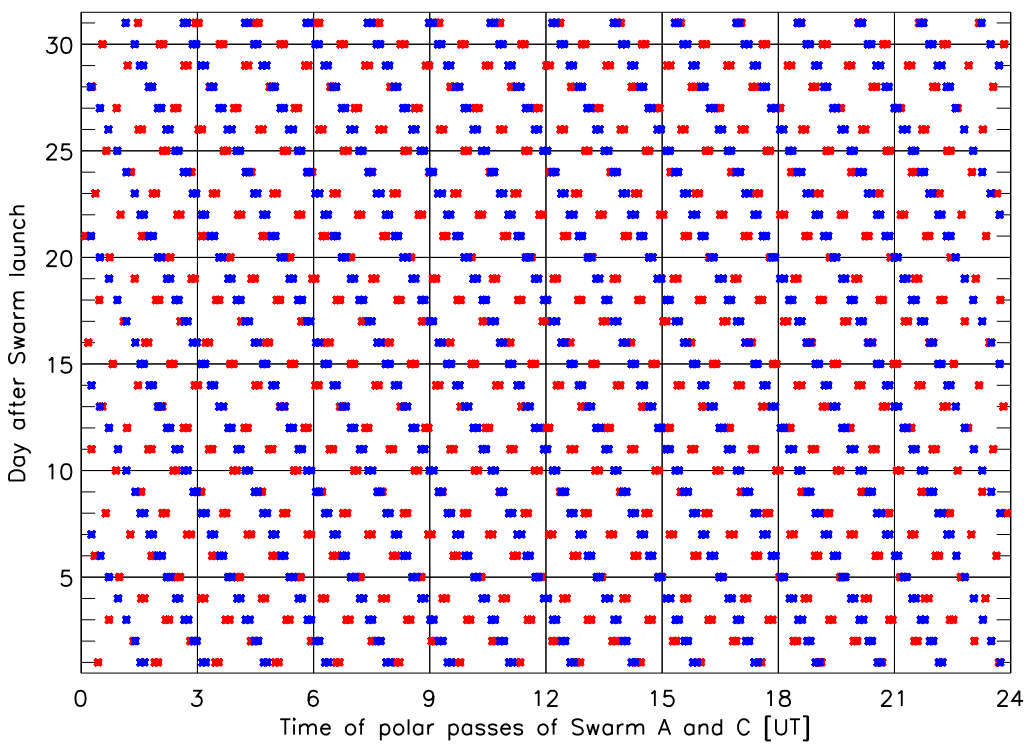

Fig. 3. Time of passing $80^{\circ}$ north geographic latitude (ascending node) for Swarm A (red) and Swarm C (blue) for the first 30 days in orbit. (See online version for colored figures.)
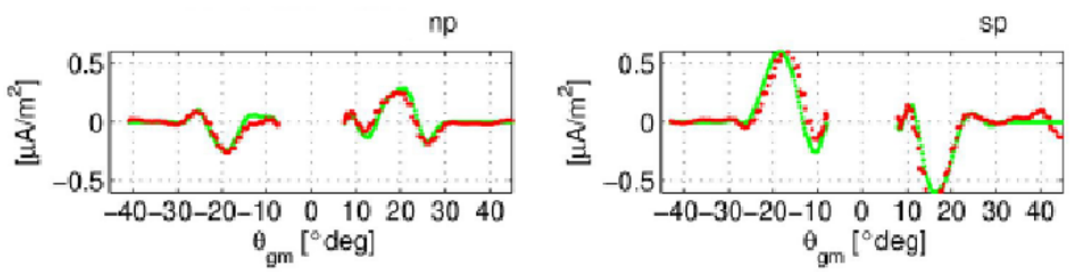

Fig. 4. Radial current density (red) derived from the lower orbiting pair of Swarm satellites A, B and the corresponding model input data (green) for the northern (np) and southern (sp) hemispheres (adapted from Ritter and Lühr, 2006). Electric current density is plotted over geomagnetic colatitude. (See online version for colored figures.)

mission is expected to be lauched in late 2013 and is planned for a nominal live time of 4 years. Its constellation consists of three circular, near-polar orbiting spacecraft. Two of them, Swarm A and B, start their orbit at an altitude of $460 \mathrm{~km}$ and descend down to $300 \mathrm{~km}$ over the mission period. Satellites A and B side-by-side fly in a formation with a longitudinal separation of about $\sim 1.4^{\circ}$ (corresponding to a distance of $160 \mathrm{~km}$ at the equator or difference of $6 \mathrm{~min}$ in local time) and the orbits cross each other near the poles. The orbit inclination is $87.4^{\circ}$. The third satellite, Swarm C, flies at a slightly higher altitude of $530 \mathrm{~km}$ with an orbital inclination of $88^{\circ}$, thus with an orbital period of about 90 seconds longer than satellites A and B. Swarm C will be in phase with A and B every 92 hours ( $\sim 4$ days) and being $180^{\circ}$ out of phase about every 46 hours ( $\sim 2$ days). This aspect is well reflected in Fig. 1 showing the tracks of the satellite orbits for the $13^{\text {th }}$ and $15^{\text {th }}$ mission day as predicted from the Swarm orbit model data (Olsen, 2004). Good global coverage is provided and orbits are nearly longitudinally aligned, at least at mid and low latitudes. The polar regions are well covered due to the frequent passes of each satellite about every 94 min, covering 
also well the magnetic poles (lower panel in Fig. 1). A polar gap of about $250 \mathrm{~km}$ in diameter occurs due to orbital inclination. Swarm A, B and Swarm C have different local time precession rates. The two lower satellites precess through 12 hours of local time in 133 days and the higher spacecraft in 144 days, resulting in a local time separation of 10 hours after 5 years mission time. Figure 2 provides examples of the orbital separation in local time at the beginning of the mission and after about 2 years.

The frequency of sampling geophysically interesting areas, for example the polar regions, is another consideration for the practicality of space weather capability. To estimate maximum time gaps between two polar observations, Fig. 3 shows the frequency of satellite passes for Swarm A and Swarm $\mathrm{C}$ at $80^{\circ}$ geographic north (ascending node). The polar sampling pattern is variable, due to the different orbital periods as dicussed above. For example, the northern polar region is sampled only about every 90 minutes on the $13^{\text {th }}$ day in orbit. On the $15^{\text {th }}$ day in orbit, the upper and the lower satellites are separated by nearly half an orbit, which results in a "sampling rate" of the north polar region almost every 45 minutes. About a doubling of the sampling can be achieved if both, northern and southern hemispheres are considered.

\section{Swarm Data as a Tool for Novel Satellite-based Space Weather Applications}

Primary official data products from the Swarm mission include calibrated time series of scalar and vector magnetic fields (1 and $50 \mathrm{~Hz}$ temporal resolution), vector electric field and plasma drift, electron density, and ion and electron temperatures ( $2 \mathrm{~Hz}$ temporal resolution) (Friis-Christensen et al., 2006). These time series are called Level-1b (L1b) products. A family of enhanced data products that are derived through appropriate mathematical algorithms using the satellite observations are called Level-2 (L2) products and monitors further parameters of the near Earth space environment. An overview of all L1b and L2 products is given in Olsen et al. (2013). Some of these products can be processed on short time delays of less than 20 minutes/day, and others provide great opportunity for further development for future space weather products. This chapter aims at introducing the potential of these products for space weather application. The usefulness of the data and their derived products cover a broad spectrum of space weather areas; among others the description of the electromagnetic environment, quantification of magnetospheric energy input into the Earth's upper atmosphere or specification of different types of ionospheric plasma structuring.

Special interest in space weather activity often focuses on the polar ionosphere. In this region, the Earth's magnetic field lines are almost vertically inclined and are connected to the magnetosphere or directly into the interplanetary magnetic field carried by the solar wind. Solar wind and magnetospheric energy can directly couple to the polar ionosphere. The ionosphere/magnetosphere coupling is reflected by typical polar ionospheric current systems and field-aligned currents connecting to magnetospheric processes (described in textbooks, e.g., Prölss, 2004; Kelley, 2009).
Swarm observations provide a multitude of possibilities to monitor and image the polar ionosphere. Based on a curlometer technique that calculates vertical electric currents from the curl of the measured magnetic field distribution ( $j \sim \nabla \times B)$, Ritter et al. (2013) derive the field-aligned current density distribution from the orbit of the lower satellite pair Swarm A and B. Using a reduced single-satellite method field-aligned currents are also obtained along the upper satellite. Figure 4 shows an example of the radial currents derived from a simulated data set described in Vennerstrøm et al. (2004). For example in the southern hemisphere the figure clearly shows that the auroral region can be found between $65^{\circ}$ and $80^{\circ}$ geomagnetic latitude $\left(25^{\circ}\right.$ and $10^{\circ}$ geomagnetic colatitude), the boundaries are estimated from the location of upward and downward radial currents activity. A continuous mapping of the orbit-by-orbit results, e.g., combined with an empirical model of the auroral oval can be suitably implemented to report on variations in the field-aligned current strength and location and width of the auroral oval. During high magnetic activity the auroral oval widens and moves equatorward (e.g. Meng, 1984).

Another indicator describing the polar activity state derived from Swarm data is the auroral electrojet, a horizontal electric current flowing in east-west direction along the auroral oval at about $110 \mathrm{~km}$. The auroral electrojet causes signatures in the vertical geomagnetic field component at satellite altitudes. This component is practically unaffected by field-aligned currents. Since almost the entire magnetic field strength is expressed by the vertical component of the geomagnetic field at high latitudes, the variations of the magnetic field strength is a suitable tool for continuous polar electrojet monitoring (e.g., Vennerstrom and Moretto, 2013). Expected amplitudes reach several tens to hundreds of nanotesla being well detectable in the magnetic data after the subtraction of an appropriate geomagnetic field model. Examples for auroral electrojet tracking based on satellite observations have been demonstrated. Using magnetic field observations of the CHAMP and Ørsted satellites Moretto et al. (2002) developed a polar electrojet index that correlated to $78 \%$ or higher with the AE-index in the northern polar region. This correlation is remarkable since the satellite samples refer to a certain local time, while the ground based AE-index represents a longitudinal average from auroral magnetic variations. Ritter et al. (2004) developed a map providing information on location and strength of the auroral electrojet every time the satellite passes the polar region. With an increasing separation of the orbital planes between Swarm satellites A, B and satellite C, and in combination with existing ground-based surveys on the location and width of the auroral oval (e.g., Johnson, 2013) different local time sectors can be monitored simultaneously and a more complete picture of auroral activity can be achieved. In such data combining tools, ground based observations will continuously provide temporal variability while space based data enhance spatial information.

Another new approach of determining high latitude ionospheric and field-aligned currents from magnetic field measurements sampled by low-orbiting satellites through one algorithm is by "spherical elementary current systems" (SECS) (Juusola et al., 2006). It was originally devel- 


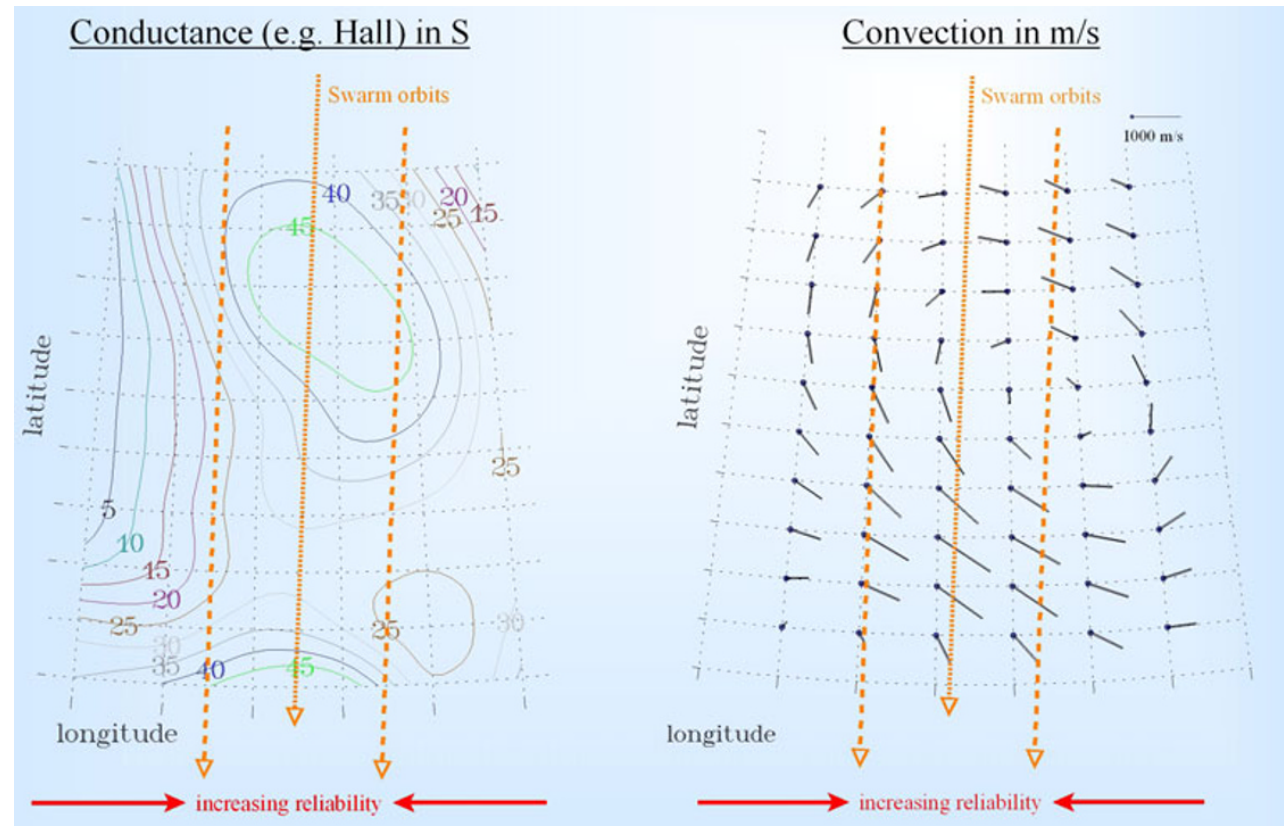

Fig. 5. Schematic example of proposed conductance and convection maps along a stripe of the Swarm orbits (from Amm et al., 2013). This example reflects a case where Swarm A, B and C are in phase. (See online version for colored figures.)

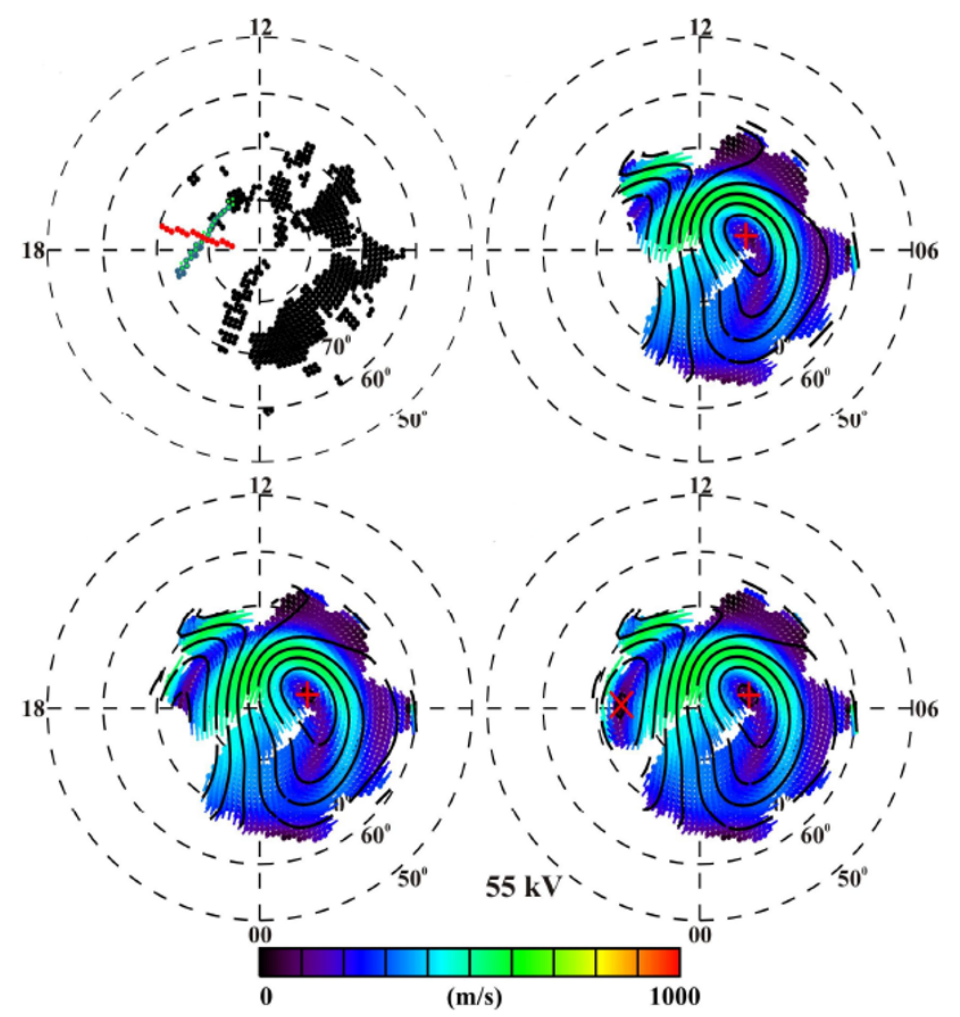

Fig. 6. (upper left) Locations for the Swarm A (blue), Swarm B (green), Swarm C (red), and SuperDARN (black) data sets. SuperDARN data locations are for January 20, 2001 11:20-11:24 UT. Convection velocity (colored scale) calculated from (upper right) SuperDARN, (lower left) SuperDARN and Swarm C, and (lower right) SuperDARN and Swarm A, and C measurements. Contours of electric potential are plotted with a 6 kV contour spacing. The plus and cross indicate the maximum and minimum potential and the cross polar cap potential is indicated where it could be determined, here on the lower left panel, where ground and Swarm A and C data have been combined (from Fioria et al., 2013). (See online version for colored figures.)

oped for ground-based geomagnetic observations by Amm (1997). The method has been tested using both modeled and real data from the CHAMP satellite, and was found to work well for the single satellite case (Juusola et al.,
2009). Multi-satellite ionospheric missions like Swarm provide information not only along a single line but along a strip that is enclosed by the spacecraft trajectories. Additional electric field measurements provide an enhanced data 
base compared to former LEO satellites like CHAMP and Ørsted. Amm et al. (2013) propose the application of the SECS method to solve for the ionospheric and field-aligned current systems. Derived electric currents and the electric field observations are then applied to solve Ohm's law for the electro-dayamics of the ionosphere resulting in maps of conductance and plasma convection along the location of the Swarm orbits. Figure 5 provides a schematic view of expected maps close to schematic Swarm satellite orbits. The reliability of the results are expected to increase in the vicinity of the observations.

For the purpose of mapping plasma convection across the entire high-latitude region, Fioria et al. (2013) propose the combination of Swarm ion drift data with SuperDARN radar velocity observations in a spherical cap harmonic analysis technique. Based on a statistical model generating the simulated data base, they investigate the value added by Swarm and found that the area of reliable convection prediction is increased by $12 \%$ when the satellite and the radar observations are sufficiently colocated. By combining the two data sets it is possible to see convection features that could otherwise not be seen with a single data set. The upper right and lower left panel of Fig. 6 show results from only SuperDARN, and combined SuperDARN and Swarm C data, respectively. Only in the lower right panel, when SuperDarn and Swarm A and C data are combined, the reconstruction of the maximum and minimum of the polar electric potential has been possible, which in turn enables the determination of the full cross polar cap potential.

Magnetospheric energy deposition into the upper atmosphere mainly happens in the polar regions and is preliminarily caused by precipitation of energetic ions and electrons and by electromagnetic energy flow, causing many secondary effects in the ionosphere and atmosphere, such as variations in ionospheric conductance, modification of plasma convection and atmospheric heating. Magnetospheric energy input is temporally variable and ranges from a few seconds to few hours, preferably enhanced during magnetic storms and substorms. Using Swarm observations, the flow of electromagnetic energy can be estimated through the Poynting flux $\mathbf{S}=1 / \mu_{0} \mathbf{E} \times \Delta \mathbf{B}$, where $\mathbf{E}$ is the electric field, $\Delta \mathbf{B}$ is the magnetic field variations caused by the currents, and $\mu_{0}$ is the magnetic permeability. Such a data product of Swarm is not yet implemented, but its significance is known from previous studies. Recently, Richmond (2010) demonstrated that the field-aligned component of the Poynting flux can under- or overestimate the electromagnetic energy dissipation depending on high or low ionospheric conductivity. More precise quantification on the energy deposite may be achieved by the divergence of the Poynting flux. The divergence can be derived from multi-satellite constellations, rather than from single satellite observations. In a preliminary study, Wilson et al. (2009) derived the Poynting flux from DMSP (Defense Meteorological Satellite Program) satellite observations and demonstrated that its magnitude is highly correlated with the intensity of particle flux, thus parameterizing the total energy transfer to a good approximation. The full estimation of energy flux, however, can only be derived from com- bined measurements of Poynting flux and particle precipitation. Knipp et al. (2011) investigated Poynting flux derived from DMSP observations on a statistical basis and detected an accumulation of extreme values at the day side cusp which they suggest to be one reason for the dayside cusp thermospheric upwelling. Swarm will monitor simultaneously thermospheric density and electron and ion temperature, three important parameters for investigating the energy depositions into the thermosphere. The Swarm satellites are not equipped with particle detectors. Energy deposition resulting from particle precipitation still needs to be quantified from radar observations or other satellite observations, e.g. DMSP in conjunction. The qualitative correlation between Poynting flux and particle precipitation, however, has been demonstrated (Wilson et al., 2009). The Swarm satellite mission will also provide products for monitoring the low-latitude ionosphere. Alken et al. (2013) propose a calculation of the dayside Equatorial Electric Field (EEF) that is derived from the inversion of magnetic field observations of the equatorial electrojet and solving for the electric field using empirical values for conductivity and thermospheric wind. Through uplifting ionospheric plasma at the equator, the dayside equatorial eastward electric field controls significantly the amplitude of the Equatorial Ionization Anomaly (EIA), with a typical response time of 2 hours (Stolle et al., 2008a). The EIA develops in the low latitude $F$ region as a double band of enhanced ionization at about $\pm 15^{\circ}$ magnetic latitude. Compared to the in situ measurements of the F region electric field along the Swarm orbits, this product may better represent the large-scale features of the low-latitude ionosphere, since it results from the inversion of the equatorial electrojet. This product may be even more suitable to predict the EIA. Although both are significantly correlated, Stolle et al. (2008a) found higher correlations coefficients between the strength of the equatorial electrojet and the EIA than between local radar observations of the equatorial electric field and the EIA.

After sunset, the low-latitude ionosphere is regularly subject to severe plasma density structuring. Since the strong electron density gradients are associated with rising depleted plasma plumes or tubes, the term equatorial plasma bubbles is often used to describe this phenomenon. Plasma bubbles occur regularly and independent of magnetic activity, but they are responsible for the most severe GPS scintillations globally (Basu et al., 2002). Post-sunset F region equatorial plasma instabilities have been studies since the 1930's (see Kelley, 2009; Woodman, 2009, for reviews), but their creation mechanisms are still not fully understood. The longitudinal alignment of the Swarm orbits provides good opportunity to identify the longitudinal distribution of bubble occurrence by their detection in satellite data. The implemented Swarm L2 product "Ionospheric Bubble Index" (IBI) identifies plasma bubbles in the magnetic observations (Park et al., 2013). The postsunset phenomenon is most intense in number and magnitude between 19 and 22 LT (e.g. Stolle et al., 2008b). With a local time precession of the satellites through 12 hours in 133 days for one node, considering both ascending and descending nodes, and a main sampling probability of bubbles for 3 hours (19-22 LT), the satellite will sample equatorial plasma ir- 


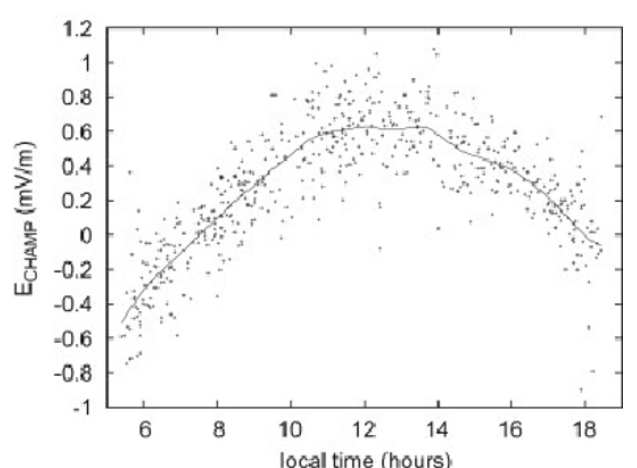

Alken and Maus (2010)

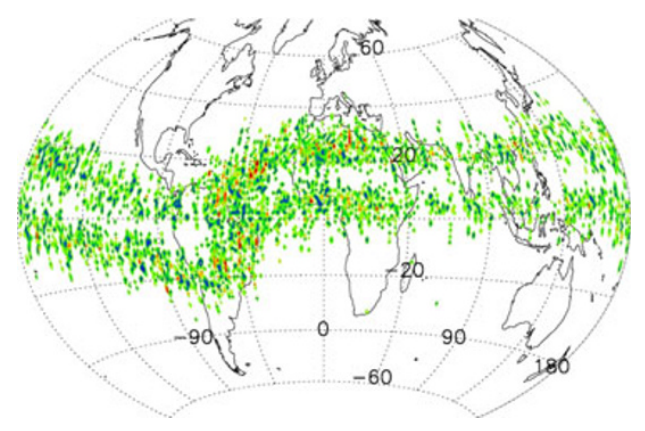

Stolle et al. (2006)

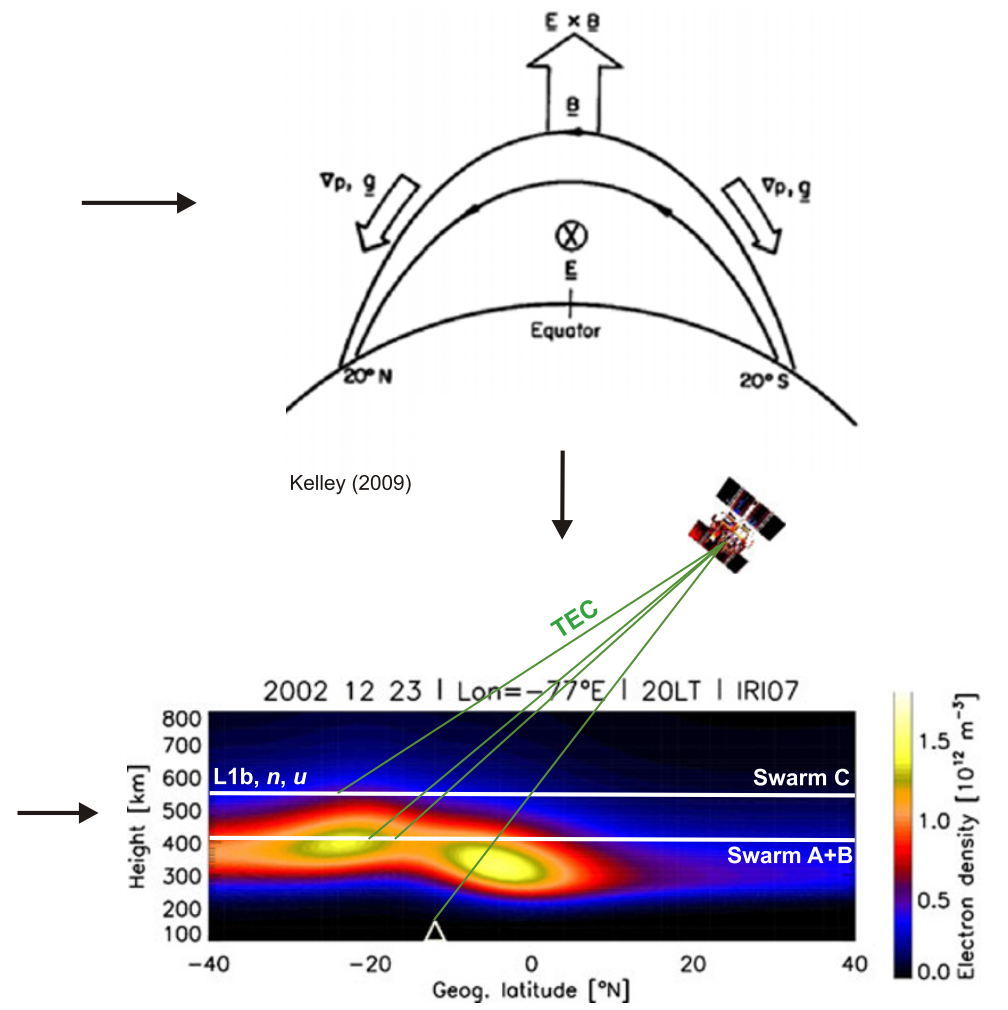

Fig. 7. Schematic view of different plasma structuring phenomena in the low latitude ionosphere. The upper row shows the local time variation of equatorial eastward electric field derived from CHAMP observations (left) that is effective in uplifting the dayside ionospheric plasma at the equator (right). The lower left panel shows an example of summed global detections of equatorial plasma bubbles in the post-sunset low latitude ionosphere derived from CHAMP observations. Information of plasma structuring together with Swarm observations (L1b and $n$, $u-$ neutral density and winds and TEC) can be used for assimilation into ionospheric background models (lower right). The figure shows a prediction of the International Reference Ionosphere (IRI) model. (See online version for colored figures.)

regularities over at least 66 days out of each 133 days of precession. Predicting capabilities from this product can be expected given the generally eastward drift of the bubble structures with drift speeds of up to 100-180 m/s (Lin et al., 2005). This can be used to forecast the arrival of a bubble at a certain longitude eastward of the detection location, e.g., $750 \mathrm{~km}$ eastward after 1.5 hours assuming an average drift speed of $140 \mathrm{~m} / \mathrm{s}$. The presently implemented Swarm product does not categorize the strength of the bubble event, e.g. depletion depths or magnetic magnitude, but simply identifies it in the magnetic and electron density observations. The quantification of the bubble strength by an enhanced detection algorithm would even increase the quality of the monitoring tool.

The Swarm satellite data will not only provide valuable products by themselves but can largely contribute as integrative data sources, e.g., to global efforts in predictive data assimilation tools for the upper atmosphere and ionosphere specifications. Such efforts try to best combine the information content from data and modeling aiming at understanding physical mechanisms that are responsible for the observed plasma and atmospheric density variations (e.g. Scherliess et al., 2009; Matsuo et al., 2013). Now- and forecasting the ionospheric and atmospheric state is the overall goal (e.g. Angling and Jackson-Booth, 2011; Schunk et al., 2012). Valuable observations provide the L1b time series of in situ plasma and magnetic field conditions continuously available along the satellite orbits with up to $2 \mathrm{~Hz}$ temporal resolution, and GPS derived total electron content observations sounding the topside ionosphere and plasmasphere (Noja et al., 2013). A novelty will be brought in by continuous observations of thermospheric density and zonal winds (Visser et al., 2013) at these low altitudes. Special benefit is expected from the satellite constellation aspect, e.g., when different local times are covered at the same time, or spatial gradient information is derived from observations of the three satellites.

Figure 7 provides examples of potential Swarm products suitable for low-ltitude phenomena described above. The upper row shows the local time variation of equatorial eastward electric field derived from CHAMP observations that is effective in uplifting the dayside ionospheric plasma at the equator. The lower left panel shows an example of summed global detections of equatorial plasma bubbles in the post-sunset low latitude ionosphere derived from CHAMP observations. Finally, Swarm in situ observations such as all L1b products, neutral density and winds, and topside TEC can be used for assimilation into ionospheric background models for imaging the present state of the ionosphere.

Also, global signatures in the geomagnetic field originating from magnetospheric currents are monitored through the Swarm mission. Based on four ground observations, magnetic storm activity is monitored by the Dst index 
(http://wdc.kugi.kyoto-u.ac.jp/dstdir) which is believed to record variations of the magnetospheric ring current. By combining a global network of magnetic observatories (Macmillan and Olsen, 2013), Olsen et al. (2011) developed an empirical model of the magnetic field from magnetospheric sources that may be used as an enhanced ring current index, that better quantifies the quiet time variations of this magnetospheric current, e.g., during non-magnetic storm activity. For the Swarm mission, Hamilton (2013) has proposed a model of the large-scale magnetic field contribution of the magnetosphere that estimates the effects of the ring current once every 90 minutes ( $\sim$ duration of one orbit). Such time sampling is more sparse than provided by the Dst index (60 minutes), but still considered sufficient to monitor large-scale variations of the magnetic storm development often taking place over several hours. In contrast to the globally averaged indices derived from ground data, the orbit-wise determination of the ring current magnetic effect refers to certain local time sectors. The fact that the magnetic signal of the ring current is local time dependent has been shown from ground and space based observations (Newell and Gjerloev, 2012; Le et al., 2011). Hamilton (2013) has shown that the Swarm satellite product could make a valuable contribution as another Dst-like index.

\section{Summary and Mission Readiness for Timely Data Availability}

Fully equipped with measurements of the electric and precise magnetic fields, plasma and neutral in situ parameters, and a GPS receiver the Swarm mission will obviously provide a valuable contribution to European and international efforts to monitor space weather. Already by themselves the observations are used to develop valuable space weather products. Combinations of Swarm data, e.g., with various networks of ground-based data, such as radars, GPS receivers or magnetometers, and other satellite data in an assimilative effort will provide an even more powerful tool for real time applications. The output of such an effort would also provide a valuable input to research activities that are continuously required to improve the quantification of space weather effects and the development of improved sophisticated products.

The scientific value of the Swarm data and the products suggested in Section 3 is outstanding and promises novel findings for describing solar-terrestrial processes. However, many of these products will significantly enhance their relevance for monitoring the present space weather when provided in timely manner. The available ground segment configuration for the Swarm mission presently allows for 2 downloads per day and per satellite at the ESA downlink station in Kiruna, Sweden resulting in data update rates of about 12 hours. The product latency is scheduled with up to three days for all L1b and selected L2 products. This delay is due to a consolidated schedule that aims at products to be processed in a single turn-around, including the most complete stage of auxiliary products. This seems not well suited for a timely description of space weather phenomena lasting only for a few hours or less. For a meaningful reduction of the product delay, data availability at the ground segment and product processing times need to be considered.
Commonly, tools applied for "near real time" rely on observations with short time delay. We consider that time delays of 90 minutes (45 minutes) corresponding to 1 (2) downloads per orbit and satellite will enable the space weather monitoring capability of many of the Swarm data products. For example, a measure of the ring current strength (proposed by Hamilton, 2013) independent of the Dst index can be provided to the international community. The detection of equatorial plasma irregularities by the ionospheric bubble index (proposed by Park et al., 2013) in combination with known zonal drift of the plasma structures can be developed in a tool to predict the location of the irregularity, that are known to live up to few hours. Electric field observations, either as direct observations from L1b or derived from magnetic observations (proposed by Alken et al., 2013) can be used to predict the strength of the equatorial ionisation anomaly, that is known to react with a response time of about 2 hours to the equatorial electric field. The algorithms implemented for all L1b products and L2 products, described in Alken et al. (2013), Noja et al. (2013), Park et al. (2013), and Ritter et al. (2013), have successfully been tested for processing times of below 20 min per day. We believe that further useful "Swarm" products will come up as soon as near-real time (once per orbit) Swarm data are available. Supporting the capabilities for fast track delivery the Swarm Mission Advisory Group has strongly recommended the implementation of a once-per-orbit near real time downlink capability for all three Swarm satellites (Mission Advisory Group, 2009). To satisfy this requirement an ESA investigation has been launched to study 15 downloads per satellite and per day at polar stations. Such an initiative would reduce the product delay time to less than 2 hours, which would enable not only its use for monitoring and prediction in the near Earth space, but would also make Swarm a demonstration mission for new space weather products from LEO satellite observations (Haagmans and the Swarm Mission Advisory Group, 2005).

Acknowledgments. We thank Nils Olsen and Freddy Christiansen for discussions on Swarm orbits and constellation. The authors gratefully acknowledge support from the European Space Agency (ESA) through ESTEC contract number 4000102140/10/NL/JA "Development of the Swarm Level 2 Algorithms and Associated Level 2 Processing Facility". PA was supported by the Institut de Physique du Globe de Paris and by the Centre National d'Études Spatiales (CNES) within the context of the "Travaux préparatoires et exploitation de la mission SWARM" project.

\section{References}

Alken, P., S. Maus, P. Vigneron, O. Sirol, and G. Hulot, Swarm SCARF equatorial electric field inversion chain, Earth Planets Space, 65, this issue, 1309-1317, 2013.

Amm, O., Ionospheric elementary current systems in spherical coordinates and their application, J. Geomag. Geoelectr., 49, 947-955, 1997.

Amm, O., K. Kauristie, C. Stolle, H. Vanhamki, N. Partamies, F. Christiansen, S. C. Buchert, H. J. Opgenoorth, M. Dunlop, F. Pitout, P. Ritter, R. Haagmans, and M. G. G. T. Taylor, Exploiting synergies between Swarm and Cluster, ESA CONTRACT No 4000106388/12/NL/BJ/lf, Finish Meteorological Institut, Report 03/2013, Helsinki, 2013.

Angling, M. J. and N. K. Jackson-Booth, A short note on the assimilation of collocated and concurrent GPS and ionosonde data into the Electron Density Assimilative Model, Radio Sci., 46, RS0D13, doi:10.1029/2010RS004566, 2011.

Basu, S., K. M. Groves, Su. Basu, and P. J. Sultan, Specification and 
forecasting of scintillations in communication/navigation links: current status and future plans, J. Atmos. Sol.-Terr. Phys., 64, 1745-1754, 2002.

Belehaki, A., Lj. Cander, B. Zolesi, J. Bremer, C. Juren, I. Stanislawska, D. Dialetis, and M. Hatzopoulos, Monitoring and forecasting the ionosphere over Europe: The DIAS project, Space Weather, 4, S12002, doi:10.1029/2006SW000270, 2006.

Fioria, R. A. D., D. H. Boteler, D. Knudsen, J. Burchill, A. V. Koustov, E. D. P. Cousins, and C. Blais, Potential impact of Swarm electric field data on global 2D convection mapping in combination with SuperDARN radar data, J. Atmos. Sol.-Terr. Phys., 93, 87-99, doi10.1016/j.jastp.2012.11.013, 2013.

Friis-Christensen, E., H. Lühr, and G. Hulot, Swarm: A constellation to Study the Earth's Magnetic Field, Earth Planets Space, 58, 351-358, 2006.

Friis-Christensen, E., H. Lühr, D. Knudsen, and R. Haagmans, SwarmAn Earth Observation Mission investigating Geospace, Adv. Space Res., 41(1), 210-216, doi:10.1016/j.asr.2006.10.008, 2008.

Haagmans, R. and the Swarm Mission Advisory Group, Swarm Mission Requirements Document for Phases B, C/D, E1, ESTEC, Noordwijk, The Netherlands, 2005.

Hamilton, B., Rapid modelling of the large-scale magnetospheric field from Swarm satellite data, Earth Planets Space, 65, this issue, 12951308, 2013.

Jakowski, N., C. Mayer, M. M. Hoque, and V. Wilken, Total electron content models and their use in ionosphere monitoring, Radio Sci., 46, RS0D18, doi:10.1029/2010RS004620, 2011.

Johnson, M. G., Real-time determination and monitoring of the auroral electrojet boundaries, J. Space Weather Space Clim., 3(A28), doi:10.1051/swsc/2013050, 2013.

Juusola, L., O. Amm, and A. Viljanen, One-dimensional spherical elementary current systems and their use for determining ionospheric currents from satellite measurements, Earth Planets Space, 58, 667-678, 2006.

Juusola, L., K. Kauristie, O. Amm, and P. Ritter, Statistical dependence of auroral ionospheric currents on solar wind and geomagnetic parameters from 5 years of CHAMP satellite data, Ann. Geophys., 27, 1005-1017, 2009.

Kappmenman, J. G., Effects of geomagnetic disturbances on power systems, IEEE Power Eng. Rev., 9(10), 15-20, 1989.

Kelley, M. C., The Earth's Ionosphere: Plasma Physics and Electrodynamic, Academic Press, Inc. San Diego, 2009.

Knipp, D., S. Eriksson, L. Kilcommons, G. Crowley, J. Lei, M. Hairston, and K. Drake, Extreme Poynting flux in the dayside thermosphere: Examples and statistics, Geophys. Res. Lett., 38, L16102, doi:10.1029/2011GL048302, 2011.

Le, G., W. J. Burke, R. F. Pfaff, H. Freudenreich, S. Maus, and H. Lühr, C/NOFS measurements of magnetic perturbations in the low-latitude ionosphere during magnetic storms, J. Geophys. Res., 116, A12230, doi:10.1029/2011JA017026, 2011.

Lin, S. L., J. T. Immel, H.-C. Yeh, S. B. Mende, and J. L. Burch, Simultaneous observations of equatorial plasma depletion by IMAGE and ROCSAT-1 satellites, J. Geophys. Res., 110, A06304, doi:10.1029/2004JA010774, 2005.

Macmillan, S. and N. Olsen, Observatory data and the Swarm mission, Earth Planets Space, 65, this issue, 1355-1362, 2013.

Manoj, C. and S. Maus, A real-time forecast service for the ionospheric equatorial zonal electric field, Space Weather, 10, S09002, doi:10.1029/2012SW000825, 2012.

Matsuo, T., I-Te Lee, and J. L. Anderson, Thermospheric mass density specification using an ensemble Kalman filter, J. Geophys. Res., 2013 (in press).

Meng, C-I., Dynamic variation of the auroral oval during intense magnetic storms, J. Geophys. Res., 89(A1), 227-235, 1984.

Mission Advisory Group, $14^{\text {th }}$ Mission Advisory Group (MAG) meeting, February, 2009.

Moretto, T., N. Olsen, P. Ritter, and G. Lu, Investigating the auroral electrojets with low altitude polar orbiting satellites, Ann. Geophys., 20, 10491061, 2002.

Newell, P. T. and J. W. Gjerloev, SuperMAG-based partial ring current indices, J. Geophys. Res., 117, A05215, doi:10.1029/2012JA017586, 2012.

Noja, M., C. Stolle, J. Park, and H. Lühr, Long-term analysis of ionospheric polar patches based on CHAMP TEC data, Radio Sci., 48, 289301, doi:10.1002/rds.20033, 2013.

Olsen, N., New parameterization of external and induced fields in geomagnetic field modeling, Geophys. Res. Abstracts, 6, 02454, 2004.

Olsen, N., A. Kuvshinov, S. Macmillan, C. Püthe, T. J. Sabaka, C. Stolle, and J. Velimsky, Scientific Report on Cat-3 Activities, Technical University of Denmark, DTU Space, Report Doc. no.: SW-RP-DTU-GS-0008, 2011.

Olsen, N., E. Friis-Christensen, R. Floberghagen, P. Alken, C. D Beggan, A. Chulliat, E. Doornbos, J. T. da Encarnação, B. Hamilton, G. Hulot, J. van den IJssel, A. Kuvshinov, V. Lesur, H. Lühr, S. Macmillan, S. Maus, M. Noja, P. E. H. Olsen, J. Park, G. Plank, C. Püthe, J. Rauberg, P. Ritter, M. Rother, T. J. Sabaka, R. Schachtschneider, O. Sirol, C. Stolle, E. Thébault, A. W. P. Thomson, L. Tøffner-Clausen, J. Velímský, P. Vigneron, and P. N. Visser, The Swarm Satellite Constellation Application and Research Facility (SCARF) and Swarm data products, Earth Planets Space, 65, this issue, 1189-1200, 2013.

Park, J., M. Noja, C. Stolle, and H. Lühr, The Ionospheric Bubble Index deduced from magnetic field and plasma observations onboard Swarm, Earth Planets Space, 65, this issue, 1333-1344, 2013.

Prölss, G. W., Physics of the Earth's Space Environment, Springer Berlin Heiderlberg New York, 2004.

Prölss, G., Density perturbations in the upper atmosphere caused by dissipation of solar wind energy, Surv. Geophys., 32, 101-195, doi:10.1007/s10712-010-9104-0, 2011.

Richmond, A. D., On the ionospheric application of Poynting's theorem, J. Geophys. Res., 115, A10311, doi:10.1029/2010JA015768, 2010.

Ritter, P. and H. Lühr, Curl-B technique applied to Swarm constellation for determing field-aligned currents, Earth Planets Space, 58, 463-476, 2006.

Ritter, P., H. Lühr, A. Viljianen, O. Amm, A. Pulkkinen, and I. Sillanp, Ionospheric currents estimated simultaneously from CHAMP satellite and IMAGE ground- based magnetic field measurements: A statistical study at auroral latitudes, Ann. Geophys., 22, 417-430, 2004.

Ritter, P., H. Lühr, and J. Rauberg, Determining field-aligned currents with the Swarm constellation mission, Earth Planets Space, 65, this issue, 1285-1294, 2013.

Scherliess, L., D. C. Thompson, and R. W. Schunk, Ionospheric dynamics and drivers obtained from a physics-based data assimilation model, Radio Sci., 44, RS0A32, doi:10.1029/2008RS004068, 2009.

Schunk, R., L. Scherliess, J. Sojka, D. Thompson, and L. Zhu, Ionospheric weather forecasting on the horizon, Space Weather, 3, S08007, doi:10.1029/2004SW000138, 2005.

Schunk, R., L. Gardner, L. Scherliess, and L. Zhu, Problems associated with uncertain parameters and missing physics for longterm ionosphere-thermosphere forecasting, Radio Sci., 47, RSOL23, doi:10.1029/2011RS004911, 2012.

Stolle, C., C. Manoj, H. Lühr, S. Maus, and P. Alken, Estimating the day time Equatorial Ionization Anomaly strength from electric field proxies, J. Geophys. Res., 113, A09310, doi:10.1029/2007JA012781, 2008a.

Stolle, C., H. Lühr, and B. G. Fejer, Relation between the occurrence rate of ESF and the equatorial plasma drift velocity at subnset derived from global observations, Ann. Geophys., 26, 1-10, $2008 \mathrm{~b}$.

Thomson, A. W. P., Geomagnetic hazards, in Encyclopedia of Geomagnetism and Paleomagnetism, edited by Gubbins, D. and E. HerreroBervera, 316-319, Springer, Netherlands, 2007.

Tsurutani, B. T., W. D. Gonzalez, Y. Kamide, and J. K. Arballo (eds.), Magnetic Storms, Geophys. Monogr. Ser., AGU Washington, 98, 266 pp., doi:10.1029/GM098, 1997.

Vennerstrøm, S., E. Friis-Christensen, H. Lühr, T. Moretto, N. Olsen, C. Manoj, P. Ritter, L. Rastätter, A. V. Kuvshinov, and S. Maus, The Impact of Combined Magnetic and Electric Field Analysis and of Ocean Circulation Effects on Swarm Mission Performance, ESA CONTRACT No 3-10901/03/NL/CB, Danish Space Research Institute, DSRI Report 2/2004, Copenhagen, 2004.

Vennerstrom, S. and T. Moretto, Monitoring auroral electrojets with satellite data, Space Weather, 11, 509-519, doi:10.1002/swe.20090, 2013.

Visser, P., E. Doornbos, J. van den IJssel, and J. T. da Encarnação, Thermospheric density and wind retrieval from Swarm observations, Earth Planets Space, 65, this issue, 1319-1331, 2013.

Wilson, G. R., W. J. Burke, D. Knipp, and K. A. Drake, Using DMSP data to quantify the energy input to the upper atmosphere, Proceedings of 2nd Swarm Workshop, http://www.congrex.nl/09c24/, 2009.

Woodman, R. F., Spread $F$-an old equatorial aeronomy problem finally resolved?, Ann. Geophys., 27(5), 1915-1934, doi:10.5194/angeo-271915-2009, 2009.

C. Stolle (e-mail: cstolle@gfz-potsdam.de), R. Floberghagen, H. Lühr, S. Maus, D. J. Knudsen, P. Alken, E. Doornbos, B. Hamilton, A. W. P. Thomson, and P. N. Visser 